\title{
Assessment of association between ankle-brachial pressure index and pulse wave velocity in patients with isolated hypertension according to gender
}

\author{
(1) Emre Tekgöz' , (1) Erhan Bozkurt², (1) Kenan Sağlam ${ }^{3}$ \\ 1 University of Health Sciences Turkey, Gülhane Faculty of Medicine, Department of Internal Medicine, Division of Rheumatology, \\ Ankara, Turkey \\ ${ }^{2}$ Afyonkarahisar Health Sciences University, Department of Internal Medicine, Afyonkarahisar, Turkey \\ 3University of Health Sciences Turkey, Gülhane Faculty of Medicine, Department of Internal Medicine, Ankara, Turkey
}

Date submitted:

31.01.2021

Date accepted:

03.03.2021

Online publication date: 15.09.2021

\section{Corresponding Author:}

Emre Tekgöz, M.D., University of Health Sciences Turkey, Gülhane Faculty of Medicine, Department of Internal Medicine, Division of Rheumatology, Ankara, Turkey dr.emretekgoz@hotmail.com

ORCID:

orcid.org/0000-0002-0866-1503

Keywords: ankle-brachial pressure index, arterial stiffness, isolated hypertension, pulse wave velocity

\begin{abstract}
Aims: Endothelial dysfunction and atherosclerosis are well-known risk factors for cardiovascular diseases in hypertension (HT). This study investigated the relationship between ankle-brachial pressure index (ABPI) and pulse wave velocity (PWV) in patients with isolated $\mathrm{HT}$ (IHT) and the difference according to gender.

Methods: This single-center, cross-sectional, and observational study was carried out between November 2014 and May 2015 in the outpatient clinic of the Department of Internal Medicine of Gülhane Military Medical Academy.

Results: The study included 90 patients with IHT (mean \pm SD age: $57.25 \pm 14.5$ years, 63.3\%

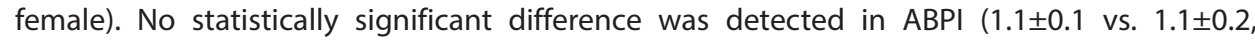
$\mathrm{p}=0.342)$ and PWV (10.9 \pm 2 vs. $10.5 \pm 1.9, \mathrm{p}=0.341)$ measurements between male and female patients. In both sexes, SBP and DBP values correlated with CAP (Female: $r=0.935, p<0.001$; $r=0.637, p<0.001$, respectively. Male: $r=0.944, p<0.001 ; r=0.749, p<0.001$, respectively). SBP values correlated with $A B P I$ among female patients $(r=-0.277, p=0.037)$ but not among male patients. DBP did not correlate with ABPI in both sexes. No correlation was found between CAP and PWV in both sexes.
\end{abstract}

Conclusions: $\mathrm{ABPI}$ and PWV values may not be alternative to each other in patients with IHT.

\section{Introduction}

Hypertension (HT) is a chronic disease that threatens public health due to its complications and has an increasing prevalence (1). The prevalence of HT in the adult population is $30.3 \%$, while it is $28.4 \%$ in males and $32.3 \%$ in females in Turkey (2). High blood pressure (BP) is a potent risk factor for the development of cardiovascular diseases (CVDs) $(3,4)$. HT is a primary factor for CVD, which is the leading cause of the death. The $50-75 \%$ of strokes and $45-55 \%$ of both myocardial infarction and also congestive heart failure detected in the population were caused by $\mathrm{HT}$.

$\mathrm{HT}$ leads to the development of endothelial dysfunction (ED) and atherosclerosis that play a crucial role in the pathogenesis of the damage of target organs (5). It has shown that ED is a precursor of atherosclerosis, which may occur prior to atherosclerosis in the presence of increased risk factors $(6,7)$. ED is the first step for the atherosclerotic process that leads to plaque formation. Also, ED induces the growth and rupture of

${ }^{\circ}$ Copyright 2021 by the University of Health Sciences Turkey, Gülhane Faculty of Medicine / Gülhane Medical Journal published by Galenos Publishing House. 
the formed plaque and triggers thrombogenic events (8). A study conducted with young patients with coronary artery disease (CAD) showed that ED was seen not only in atherosclerotic vessels, but also in non-atherosclerotic vessels (9). It is thought that ED may indicate the tendency for the development of atherosclerosis. Also, the presence of ED may be a bad prognostic indicator in CVDs (10). To evaluate the presence of atherosclerosis and the potential stiffness of the vessel wall, Ankle-Brachial Pressure Index (ABPI) and pulse wave velocity (PWV) can be used as non-invasive methods.

Measurement of ABPI is an inexpensive and easy-toimplement method. It can be calculated by dividing the ankle systolic pressure value by the simultaneously measured brachial systolic pressure value. Regularly, the systolic pressure measured in the ankle is equal to or greater than the systolic pressure measured in the arm. Therefore, the normal ABPI value is equal to or greater than 1 , but, due to technical differences in measurements and acceptable mild vascular stenosis, the values above 0.90 are considered as normal (11). Lower levels of ABPI $(<0.90)$ can predict CVDs and atherosclerosis. Additionally, an $A B P I$ value equal to or lower than 0.90 has $90 \%$ sensitivity and $98 \%$ specificity for peripheral artery disease (PAD) (12). Whereas, a low ABPI value can be used for confirmation of PAD, and also, it may indicate the presence of PAD in asymptomatic patients (13). Low levels of ABPI may be an indicator for poor prognosis in long-term risk assessment in patients with PAD. A 3- to 6-fold increased risk of death due to CVD is associated with low ABPI values. On the other hand, high ABPI (>1.4) has also been found to be associated with an increased mortality rate (14).

In the assessment of arterial stiffness, various parameters have been defined. Because of the difficulty in the application of catheter-based interventional measurements, noninvasive methods have been developed. Measurement of PWV by using an arterial tonometer is a frequently used noninvasive method for determining arterial stiffness. Left ventricle contracts provide the strength to push the blood through the ascending aorta, which creates a pressure wave on the arterial vessels of the whole body. The spreading speed of this wave is PWV, which is an indicator for arterial stiffness (15). As arterial stiffness increases, PWV spreading through the arterial system also increases $(16,17)$. The higher the PWV, the weaker the arterial expansion ability (distensibility) (15). According to the 2013 criteria of the European Society of Cardiology and the European Society of $\mathrm{HT}$ (ESC/ESH), the threshold value of PWV is determined as $10 \mathrm{~m} / \mathrm{s}$ (18). The increase in PWV leads to an early reflection and a faster access of the pulse wave to the periphery vessels. The attainment of the reflected wave to the heart removes from diastole to systole with time. Consequently, a rise in arterial stiffness causes an increased pressure at the aortic root, also named central aortic pressure (CAP), in late systole, decreased pressure in diastole, and an increase in mean arterial pressure (19). Measurement of ABPI and PWV can predict the presence of aggravated atherosclerosis and arterial stiffness, and may aware physicians of increased CVD risk in patients with HT.

This study aimed to evaluate the relationship between ABPI and PWV values in male and female patients with $\mathrm{HT}$, the role of these parameters to get precautions for CVD and providing contributions to the follow-up and treatment of CVD.

\section{Methods}

\section{Study Design and Patient Selection}

This was a single-center, cross-sectional, and observational study that was carried out between November 2014 and May 2015 in the outpatient clinic of the Department of Internal Medicine of Gülhane Military Medical Academy, Ankara, Turkey. A total of 90 patients who were followed up with isolated HT (IHT) according to the recommendations of the $2013 \mathrm{ESC} / \mathrm{ESH}$ guidelines were included in the study (18). Written informed consents were obtained from all participants.

HT was defined as a systolic BP (SBP) equal to and greater than $140 \mathrm{mmHg}$ and a diastolic BP (DBP) equal to and greater than $90 \mathrm{mmHg}$, or elevated BP that increases the risk of damage in the target organs such as the heart, brain, kidney, and retina. Participants' age, gender, smoking status, comorbid diseases, and medications were recorded. Biochemical parameters including renal function tests, transaminase levels, serum lipid profile, and blood glucose levels, and complete blood count levels which were evaluated within three months were recorded in the patients' follow-up forms. Body mass index (BMI) calculated by dividing weight by height squared $\left(\mathrm{kg} / \mathrm{m}^{2}\right)$ was recorded for each participant. Patients who had malignancies, diabetes mellitus (DM), hyperlipidemia, PAD, CAD, and thyroid disease, who were under 18 years old, and who did not approve to participate in the study were excluded from the study.

\section{Measurement of ABPI}

ABPI measurement was made by a trained physician with a hand-held Doppler probe (Hadeco, Japan) and calibrated standard sphygmomanometers with a $12 \mathrm{~cm}$ cuff width (ERKA, D-83646, Germany) in an isolated room. The patients rested for at least 5 minutes before the measurement. ABPI measurement was performed while the patient was lying in the supine position with a cuff wrapped around just above both arms and ankles, beginning from the right arm. Consequtive measurements were taken from the right leg, the left leg and the left arm. The handheld Doppler device placed on the brachial artery, the anterior tibial artery, and the posterior tibial artery determined SBP. While deflating the cuff slowly, the first pulse detected from the Doppler was noted as BP. The highest value of right and left brachial pressure was noted as the value of the upper extremity. The procedure was repeated for both right and left anterior and 
posterior tibialis arteries and the highest value was accepted as the ankle pressure. ABPI was calculated for both right and left by dividing the lower extremity value by the upper extremity value. The lowest value from the right and left extremity was accepted as the ABPI value of the patient.

\section{Measurement of PWV}

PWV measurement was performed by The TensioMed (Budapest, Hungary) brand arteriography, in an isolated room after a rest for at least 5 minutes in the supine position. Smoking and caffeinated beverages were stopped within 30 minutes before measurement. The distance between the jugular notch and the symphysis pubis was measured and recorded in the device in centimeters. After the pressure was measured with the arteriography device, the cuff was inflated at least $35 \mathrm{mmHg}$ above the systolic pressure value detected simultaneously. During the measurement (for 8-20 seconds), the blood flow cessation was provided by the complete brachial artery occlusion. The signals obtained were transferred to the computer and analyzed to receive SBP, DBP, central aortic (or aortic) pressure 'CAP', and PWV values automatically by the device.

\section{Statistical Analysis}

Statistical analyses were performed using IBM Statistical Package for the Social Sciences for Windows version 21.0 package program (Armonk, NY: IBM). Numerical variables were summarized with mean \pm standard deviation or median (minimum-maximum) values, and categorical variables with numbers and percentages. Whether numerical variables showed normal distribution or not was examined using the Kolmogorov-Smirnov test. Similarity of group variances was investigated by the Levene test. Difference between the two groups in terms of numerical variables (if any) was investigated using the t-test in independent groups if the parametric test assumptions were met, and with the Mann-Whitney $U$ test if not. Whether there was a difference between the groups in terms of categorical variables was examined using the chi-square test. The relationship between numerical variables was evaluated with the Pearson correlation coefficient. Level of statistical significance was accepted as $p<0.05$.

\section{Results}

A total of 90 patients with IHT, including $33(36.7 \%)$ male and $57(63.3 \%)$ female, were included in the current study. The mean age of the patients was $57.3 \pm 14.5$ years. According to the 2013 ESC/ESH guideline, 5 (5.6\%) patients had optimal BP, 9 (10\%) had normal BP, 12 (13.3\%) had high-normal BP, $38(42.2 \%)$ had stage $1 \mathrm{HT}, 15$ (16.7\%) had stage $2 \mathrm{HT}$, and 11 (12.2\%) had stage $3 \mathrm{HT}$. There was no significant difference between male and female patient groups in terms of HT stages $(p>0.05)$. Female patients had higher BMI and waist circumference than male patients $(p<0.001$ and $p=0.002$, respectively), whereas male patients were taller than female patients $(p<0.001)$. The smoking rate was higher among males than females $(p=0.002)$. Forty-seven (82.5\%) female patients and 27 (81.8\%) male patients were receiving treatment for HT $(p>0.05)$. There was no difference between male and female patients in terms of the number of antihypertensive drugs used $(p>0.05)$ (Table 1).

The mean value of PWV was $10.9 \pm 2 \mathrm{~m} / \mathrm{s}$ in male patients and $10.5 \pm 1.9 \mathrm{~m} / \mathrm{s}$ in female patients $(p=0.341)$. The mean $A B P I$ value was $1.1 \pm 0.1$ in male patients and $1.1 \pm 0.2$ in female patients $(p=0.342)$. Normal ABPI values were present in 60 $(66.7 \%)$ patients, whereas $10(11.1 \%)$ patients had low values, $19(21.1 \%)$ patients had borderline ABPI values, one (1.1\%) patient had high $A B P I$ value (Table 2). In female patients, as BP increased, CAP increased and ABPI values decreased $(p=<0.001$ and $p=0.003$, respectively). In male patients, as arterial BP increased, CAP increased $(p=<0.001)$. There was no relationship between arterial BP and PWV values in male or female patients (Table 3).

A positively significant correlation was present between CAP and values of SBP and DBP in female and male patients. On the other hand, a significant negative correlation was present between ABPI and SBP values in female patients. There was no relationship between $\mathrm{ABPI}$ and $\mathrm{PWV}$ values in male and female patients (Table 4).

\section{Discussion}

Determination of arterial stiffness and atherosclerosis with non-invasive methods in patients with increased risk for CVD is inexpensive and these methods are easily applicable methods that help physicians in follow-up and treatment course of CVDs. The current study evaluated arterial stiffness and atherosclerosis by non-invasive methods and showed that, because of the relationship between $\mathrm{ABPI}$ and $\mathrm{SBP}$, these patients should be assessed for PAD cautiously. Additionally, according to the findings of the current study, PWV and ABPI cannot be used instead of each other.

ED may appear as an important risk factor for CVD in the early stages of atherosclerosis. Detection of ED at early stages may provide early diagnosis, effective treatment, and follow-up for CVD. Therefore, recent studies tried to reveal parameters that recognize CVD earlier by assessing arterial stiffness. To investigate the relationship between the risk of CVD and arterial stiffness parameters, 2,232 participants were assessed in the Framingham Heart Study, which showed higher PWV values were related to an increased risk for CVD (20). According to the study performed by Scuteri with 4,000 participants who were followed-up for 9.4 years, the increase of BP with age did not directly influence PWV, besides, gender and the other factors that lead to arterial stiffness might affect SBP, PWV and pulse pressure (21). In the current study, though it was not statistically 


\begin{tabular}{|c|c|c|c|c|}
\hline & & Female $(n=57)$ & Male $(n=33)$ & $\mathbf{p}$ \\
\hline \multicolumn{2}{|l|}{$\mathrm{Age}^{*}$} & $58.6 \pm 14.2$ & $55.9 \pm 16.6$ & $0.417^{a}$ \\
\hline \multicolumn{2}{|l|}{ Weight $(\mathrm{kg})^{*}$} & $82 \pm 13.7$ & $81.5 \pm 14.1$ & $0.865^{a}$ \\
\hline \multicolumn{2}{|l|}{ BMI $\left(\mathrm{kg} / \mathrm{m}^{2}\right)^{*}$} & $32.4 \pm 5.6$ & $27.5 \pm 4.3$ & $<0.001^{a}$ \\
\hline \multicolumn{2}{|l|}{$\mathrm{DBP}(\mathrm{mmHg})^{*}$} & $87.7 \pm 10.4$ & $88.4 \pm 12.9$ & $0.813^{a}$ \\
\hline \multicolumn{2}{|l|}{ Mean AP $(\mathrm{mmHg})^{*}$} & $108.5 \pm 13.7$ & $109.5 \pm 16.1$ & $0.769^{a}$ \\
\hline \multirow{2}{*}{ Smoking } & Yes, n (\%) & $9(15.8)$ & $16(48.5)$ & \multirow{2}{*}{$0.002^{b}$} \\
\hline & No, $n(\%)$ & $48(84.2)$ & $17(51.5)$ & \\
\hline \multicolumn{2}{|l|}{ Leucocyte $\left(/ \mathrm{mm}^{3}\right)^{*}$} & $6904.7 \pm 1494.7$ & $7452.1 \pm 1960.8$ & $0.140^{\mathrm{a}}$ \\
\hline \multicolumn{2}{|l|}{ Hemoglobin $(\mathrm{g} / \mathrm{dL})^{*}$} & $13.3 \pm 1.4$ & $15.3 \pm 1.6$ & $<0.001^{a}$ \\
\hline \multicolumn{2}{|c|}{ Thrombocyte $\left(x 1000 / \mathrm{mm}^{3}\right)^{*}$} & $277.3 \pm 66.8$ & $245.8 \pm 61.4$ & $0.029^{a}$ \\
\hline \multicolumn{2}{|l|}{ Creatinine $(\mathrm{mg} / \mathrm{dL})^{*}$} & $0.9 \pm 0.2$ & $1.1 \pm 0.3$ & $<0.001^{a}$ \\
\hline \multicolumn{2}{|c|}{ Sedimentation $(\mathrm{mm} / \mathrm{h})^{*}$} & $22.3 \pm 13.2$ & $13.9 \pm 12.2$ & $0.005^{a}$ \\
\hline
\end{tabular}

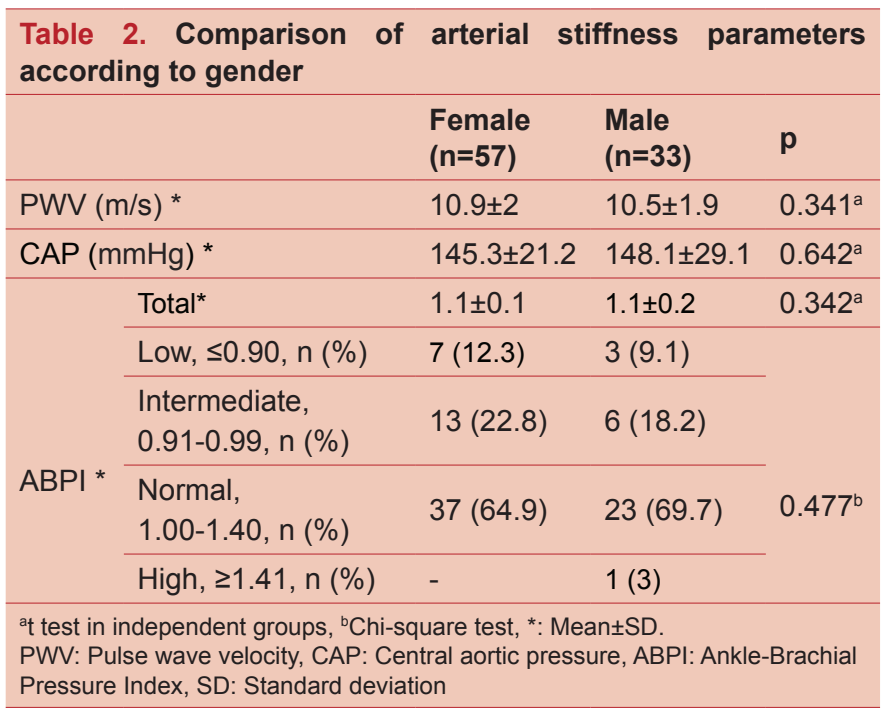

significant, an increase in PWV was found with increasing SBP similar to the study performed by Scuteri et al. (21). However, increased systolic and DBP were strongly associated with increased CAP.

In CVD, increased CAP due to the early return of the reflected wave in late systole develops additional load on the ventricle, and consequently causes a decrease in ejection fraction, a rise in the requirement of myocardial oxygen, and increase in mortality (22). Totaro et al. (23) investigated 430 normotensive participants and showed that $16 \%$ of the participants had high CAP levels and increased risk for target organ damage. There was a relationship between high central BP and early cardiovascular dysfunction. Similarly, a meta-analysis of 11 studies with a total of 5,488 cases presented by Vlachopoulos et al. (24) found out that an increase of $10 \mathrm{mmHg}$ in CAP was associated with mortality related to CVD. In this respect, as recommended by guidelines in new-onset $\mathrm{HT}$, in addition to the measurement of PWV, measuring CAP associated with BP levels may be crucial in the treatment and follow-up of patients with HT.

HT, DM, hyperlipidemia, smoking and aging are risk factors associated with both atherosclerosis and PAD (25). Most of the patients with PAD have risk factors for CVD. Ness et al. (26) demonstrated that $\mathrm{HT}$ was an independent risk factor for PAD. Albuquerque et al. (27) found out that patients with $\mathrm{HT}$, who had low ABPI levels but without clinical complaints associated with PAD, had increased risk for left ventricular hypertrophy and CVD. High also low ABPI levels in patients with HT were found to be related to death and CVD (28). When participants without HT were followed-up for 47 months, the development of $\mathrm{HT}$ was found to be related to normal or high ABPI levels at the beginning (29). Similar to the literature, the current study showed a relationship between BP and ABPI levels in female patients. CVD risk factors, such as $H T$, that pose a risk for atherosclerosis and PAD may play a role in long-term morbidity and mortality rates. Physicians should be aware of applying 


\begin{tabular}{|c|c|c|c|c|c|c|c|}
\hline Female & Optimal & Normal & High normal & Stage $1 \mathrm{HT}$ & Stage $2 \mathrm{HT}$ & Stage $3 \mathrm{HT}$ & $\mathrm{p}$ \\
\hline $\begin{array}{l}\mathrm{PWV}^{*} \\
(\mathrm{~m} / \mathrm{s})\end{array}$ & $\begin{array}{l}10.3 \\
(9.0-11.9)\end{array}$ & $\begin{array}{l}11.1 \\
(8.8-12.7)\end{array}$ & $\begin{array}{l}10.5 \\
(6.9-14.6)\end{array}$ & $\begin{array}{l}10.8 \\
(8.3-14.5)\end{array}$ & $\begin{array}{l}10.6 \\
(8.5-14)\end{array}$ & $\begin{array}{l}10.1 \\
(8.3-16)\end{array}$ & 0.890 \\
\hline $\begin{array}{l}\mathrm{CAP}^{*} \\
(\mathrm{mmHg})\end{array}$ & $\begin{array}{l}115.3 \\
(108.6-119.4)\end{array}$ & $\begin{array}{l}119.2 \\
(112.4-133.3)\end{array}$ & $\begin{array}{l}127.4 \\
(122-141.8)\end{array}$ & $\begin{array}{l}147.0 \\
(126.1-159)\end{array}$ & $\begin{array}{l}156.5 \\
(143.9-178.5)\end{array}$ & $\begin{array}{l}194.4 \\
(178.7-219.5)\end{array}$ & $<0.001$ \\
\hline $\mathrm{ABPI}^{*}$ & $1.0(1.0-1.08)$ & $1.0(0.87-1.12)$ & $\begin{array}{l}1.0 \\
(0.85-1.29)\end{array}$ & $\begin{array}{l}1.1 \\
(0.86-1.25)\end{array}$ & $\begin{array}{l}1.0 \\
(0.91-1.26)\end{array}$ & $\begin{array}{l}0.9 \\
(0.81-0.95)\end{array}$ & 0.003 \\
\hline Male & Optimal & Normal & High normal & Stage $1 \mathrm{HT}$ & Stage $2 \mathrm{HT}$ & Stage $3 \mathrm{HT}$ & $\mathbf{p}$ \\
\hline $\begin{array}{l}\mathrm{PWV}^{*} \\
(\mathrm{~m} / \mathrm{s})\end{array}$ & $9.4(8.1-10.7)$ & $\begin{array}{l}9.5 \\
(7.4-11.8)\end{array}$ & $\begin{array}{l}8.8 \\
(8.3-13.5)\end{array}$ & $\begin{array}{l}10.4 \\
(7-15.3)\end{array}$ & $\begin{array}{l}10.1 \\
(9.7-11.1)\end{array}$ & $\begin{array}{l}11.8 \\
(8.5-13.4)\end{array}$ & 0.695 \\
\hline $\begin{array}{l}\mathrm{CAP}^{*} \\
(\mathrm{mmHg})\end{array}$ & $\begin{array}{l}106.6 \\
(102.7-110.5)\end{array}$ & $\begin{array}{l}118.5 \\
(108.5-122.0)\end{array}$ & $\begin{array}{l}131 \\
(123.8-138.0)\end{array}$ & $\begin{array}{l}143.7 \\
(119.7-156.4)\end{array}$ & $\begin{array}{l}167.5 \\
(154-185.8)\end{array}$ & $\begin{array}{l}190 \\
(155.3-212.1)\end{array}$ & $<0.001$ \\
\hline $\mathrm{ABPI}^{*}$ & $1.1(1-1.28)$ & $1.1(0.96-1.23)$ & $\begin{array}{l}1.1 \\
(0.99-1.63)\end{array}$ & $\begin{array}{l}1.1 \\
(0.9-1.19)\end{array}$ & $\begin{array}{l}1.1 \\
(0.85-1.18)\end{array}$ & $\begin{array}{l}1.0 \\
(0.85-1.28)\end{array}$ & 0.889 \\
\hline
\end{tabular}

\begin{tabular}{|c|c|c|c|c|}
\hline & \multicolumn{4}{|l|}{ CAP } \\
\hline & \multicolumn{2}{|l|}{ Female } & \multicolumn{2}{|l|}{ Male } \\
\hline & $\mathbf{r}$ & $\mathbf{p}$ & $r$ & $\mathbf{p}$ \\
\hline $\mathrm{SBP}(\mathrm{mmHg})$ & 0.935 & $<0.001$ & 0.944 & $<0.001$ \\
\hline \multirow[t]{2}{*}{$\mathrm{DBP}(\mathrm{mmHg})$} & 0.637 & $<0.001$ & 0.749 & $<0.001$ \\
\hline & \multicolumn{4}{|l|}{ ABPI } \\
\hline PWV (m/s) & -0.071 & 0.600 & -0.229 & 0.199 \\
\hline $\mathrm{CAP}(\mathrm{mmHg})$ & -0.204 & 0.128 & -0.116 & 0.522 \\
\hline $\mathrm{SBP}(\mathrm{mmHg})$ & -0.277 & 0.037 & -0.154 & 0.393 \\
\hline $\mathrm{DBP}(\mathrm{mmHg})$ & -0.154 & 0.253 & -0.061 & 0.734 \\
\hline \multicolumn{5}{|c|}{$\begin{array}{l}\text { Pearson correlation coefficient. } \\
\text { SBP: Systolic blood pressure, DBP: Diastolic blood pressure, PWV: Pulse } \\
\text { wave velocity, CAP: Central aortic pressure, ABPI: Ankle-Brachial Pressure } \\
\text { Index }\end{array}$} \\
\hline
\end{tabular}

protective measures and should treat CVD risk factors. There are limited data in the literature regarding the comparison of arterial stiffness and $A B P I$ measurements. A recent study presented that $A B P I$ values were associated with $P W V$ in nondiabetic patients with PAD (30). Patients without CVD at baseline were followed up for 8.5 years by $\mathrm{Zi}$ et al. (31). At the end of the follow-up time, significant increases in vascular stiffness and PWV were recognized in patients with low ABPI levels at baseline. In a study, which evaluated arterial stiffness and ABPI values in patients without $P A D$, no statistically significant relationship between PWV and ABPI was found (32). In our study, to exclude the effect of gender-related factors, such as hormonal status and muscle mass, levels of PWV and ABPI were evaluated in male and female patients. Similar to the study performed by Rabkin et al. (32), the current study found no relationship between ABPI values and PWV in female and male patients with $\mathrm{HT}$ and without PAD.
Our study had some limitations. To evaluate the differences between hypertensive and normotensive individuals, normotensive healthy individuals as a control group could be included in the study. To investigate the effect of treatment on arterial stiffness parameters, patients could be separated into groups according to the treatment. Further studies with larger samples in prospective design will address more accurate information about the clinical importance of ABPI and PWV.

\section{Conclusion}

In conclusion, PWV and $\mathrm{ABI}$ measurements, which are the noninvasive indicators of arterial stiffness and atherosclerosis related to vascular remodeling due to $\mathrm{HT}$, could not be used instead of each other. Additionally, due to the relationship between BP levels and CAP and the relationship between SBP and ABPI especially in female patients, high CAP and low ABPI levels should be considered to provide the early diagnosis, effective treatment, and prevention from cardiovascular morbidity and mortality in patients with HT.

\section{Ethics}

Ethics Committee Approval: The study was approved by the Gülhane Military Medical Academy Ethics Committee (Code: 1491-585-14/1648.4-2006, date: 10.14.2014).

Informed Consent: Verbal and written informed consents were obtained from all participants.

Peer-review: Internally and externally peer-reviewed.

\section{Authorship Contributions}

Surgical and Medical Practices: E.T., E.B., K.S., Concept: E.T., E.B., K.S., Design: E.T., E.B., K.S., Data Collection or Processing: E.T., K.S., Analysis or Interpretation: E.T., E.B., K.S., Literature Search: E.T., E.B., K.S., Writing: E.T., E.B., K.S. 
Conflict of Interest: No conflict of interest was declared by the authors.

Financial Disclosure: The authors declared that this study received no financial support.

\section{References}

1. Wolf-Maier K, Cooper RS, Banegas JR, et al. Hypertension prevalence and blood pressure levels in 6 European countries, Canada, and the United States. JAMA. 2003;289:2363-2369.

2. Altun B, Erdem Y, Derici U. Turkish Hypertension Prevalence Study (PatenT 2). Turkish Society of Hypertension and Kidney Diseases. 2012;1-27.

3. Kannel WB. Blood pressure as a cardiovascular risk factor: prevention and treatment. JAMA 1996;275:1571-1576.

4. Dego TR, Bobasa EM. Adherence to anti-hypertensive medication and contributing factors among non-comorbid hypertensive patients in two hospitals of jimma town, south west ethiopia. Gülhane Tip Dergisi. 2016;58:60-66.

5. Chalmers J, MacMahon S, Mancia G, et al. 1999 World Health Organization-International Society of Hypertension Guidelines for the management of hypertension. Guidelines sub-committee of the World Health Organization. Clin Exp Hypertens. 1999;21:1009-1060.

6. Celermajer DS, Sorensen KE, Gooch VM, et al. Noninvasive detection of endothelial dysfunction in children and adults at risk of atherosclerosis. Lancet. 1992;340:11111115.

7. Versari D, Daghini E, Virdis A, et al. Endotheliumdependent contractions and endothelial dysfunction in human hypertension. Br J Pharmacol. 2009;157:527-536.

8. Esper RJ, Nordaby RA, Vilariño JO, et al. Endothelial dysfunction: a comprehensive appraisal. Cardiovasc Diabetol. 2006;5:4.

9. Lieberman EH, Gerhard MD, Uehata A, et al. Flow-induced vasodilation of the human brachial artery is impaired in patients $<40$ years of age with coronary artery disease. Am J Cardiol. 1996;78:1210-1214.

10. Turkey Endocrinology and Metabolism Society. Metabolic Syndrome Guide. Ankara: Tuna Matbaacılık; 2009:8-11.

11. Labropoulos N, Giannoukas AD, Volteas N, et al. Early hemodynamic effects of percutaneous transluminal angioplasty in patients with superficial femoral artery disease. Vasc Surg. 1997;31:615-621.

12. Başgöz BB, Taşcı İ, Yıldız B, Demirbaş Ş, Sağlam K, Açıkel C.Sensitivity, specificity and predictive value of the edinburgh claudication questionnaire versus ankle-brachial index for the diagnosis of lower extremity arterial disease in Turkish adults. Gulhane Med J. 2016;58:177-183.

13. Fowkes FG, Price JF, Stewart MC, et al. Aspirin for prevention of cardiovascular events in a general population screened for a low ankle brachial index: a randomized controlled trial. JAMA. 2010;303:841-848.
14. Criqui $\mathrm{MH}, \mathrm{McClelland} \mathrm{RL}$, McDermott $\mathrm{MM}$, et al. The ankle-brachial index and incident cardiovascular events in the MESA (Multi-Ethnic Study of Atherosclerosis). J Am Coll Cardiol. 2010;56:1506-1512.

15. Syeda B, Gottsauner-Wolf M, Denk S, Pichler P, Khorsand A, Glogar D. Arterial compliance: a diagnostic marker for atherosclerotic plaque burden? Am J Hypertens. 2003;16:356-362.

16. Taddei S, Virdis A, Ghiadoni L, et al. Age-related reduction of NO availability and oxidative stress in humans. Hypertension. 2001;38:274-279.

17. Laurent $S$, Boutouyrie P, Asmar R, et al. Aortic stiffness is an independent predictor of all-cause and cardiovascular mortality in hypertensive patients. Hypertension. 2001;37:1236-1241.

18. Council ES, Redon J, Narkiewicz K, et al. 2013 ESH/ESC Guidelines for the management of arterial hypertension. Eur Heart J. 2013;34:2159-2219.

19. Pannier B, Guérin AP, Marchais SJ, Safar ME, London GM. Stiffness of capacitive and conduit arteries: prognostic significance for end-stage renal disease patients. Hypertension. 2005;45:592-596.

20. Mitchell GF, Hwang SJ, Vasan RS, et al. Arterial stiffness and cardiovascular events: the Framingham Heart Study. Circulation. 2010;121:505-511.

21. Scuteri $A$, Morrell $\mathrm{CH}$, Orrù $\mathrm{M}$, et al. Longitudinal perspective on the conundrum of central arterial stiffness, blood pressure, and aging. Hypertension. 2014;64:12191227.

22. Laurent $S$, Boutouyrie $P$, Asmar $R$, et al. Aortic stiffness is an independent predictor of all-cause and cardiovascular mortality in hypertensive patients. Hypertension. 2001;37:1236-1241.

23. Totaro S, Khoury PR, Kimball TR, Dolan LM, Urbina EM. Arterial stiffness is increased in young normotensive subjects with high central blood pressure. J Am Soc Hypertens. 2015;9:285-292.

24. Vlachopoulos C, Aznaouridis K, Stefanadis C. Prediction of cardiovascular events and all-cause mortality with arterial stiffness: a systematic review and meta-analysis. J Am Coll Cardiol. 2010;55:1318-1327.

25. Haymana C, Aydogdu A, Tasci I, et al. Assessment of a low ankle brachial index in young males with congenital hypogonadism. Gülhane Tip Dergisi. 2017;59:11-15.

26. Ness J, Aronow WS, Ahn C. Risk factors for symptomatic peripheral arterial disease in older persons in an academic hospital-based geriatrics practice. J Am Geriatr Soc. 2000;48:312-314.

27. Albuquerque PF, Albuquerque $\mathrm{PH}$, Albuquerque $\mathrm{GO}$, Servantes DM, Carvalho SM, Oliveira Filho JA. Anklebrachial index and ventricular hypertrophy in arterial hypertension. Arq Bras Cardiol. 2012;98:84-86.

28. Alves-Cabratosa L, Elosua-Bayes M, García-Gil M, et al. Hypertension and high ankle brachial index: the overlooked combination. J Hypertens. 2019;37:92-98. 
29. Ishida A, Kinjo K, Maeda T, Ohya Y. Association between high-normal ankle-brachial index and hypertension incidence: the Okinawa Peripheral Arterial Disease Study. J Hypertens. 2019;37:935-941.

30. Khandanpour N, Armon MP, Jennings B, Clark A, Meyer FJ. The association between ankle brachial pressure index and pulse wave velocity: clinical implication of pulse wave velocity. Angiology. 2009;60:732-738.
31. Zi $\mathrm{Y}$, Coutinho $\mathrm{T}$, Iftikhar $\mathrm{K}$. Ankle-Brachial Index Predicts Progression of Aortic Stiffeness. Circulation. 2014;130:A17983.

32. Rabkin SW, Chan SH, Sweeney C. Ankle-brachial index as an indicator of arterial stiffness in patients without peripheral artery disease. Angiology. 2012;63:150-154. 